fund research as it approaches commercial viability. But if government does not fund broadly targeted basic research, no one else will, and the foundations of a commercially viable technology will be undermined.

In addition, if the NIH takes the next step, as MacLean suggests, and starts to see itself as a profit-making body competing with, rather than being a resource for, private industry, government research policy is more likely to be directed toward short term goals of institutional self-promotion, and commercial goals would tend to edge out longer term goals necessary for optimal research progress. The $\mathrm{NIH}$ is thus increasingly likely to end up with its institutional interests influencing its position on science policy issues, both internally and even in the broader national science policy arena, as we are now seeing with the cDNA patent case.

Michael Syvanen

Professor, School of Medicine Dept. of Medical Microbiology and Immunology University of California, Davis

Davis, CA 95616

\section{Lilly's Humatrope Experience}

\section{To the editor:}

Eli Lilly and Company is a research-based corporation that develops, manufactures, and markets high-technology medical products, including pharmaceuticals. We appreciate the invitation to share our views regarding the development of new drugs for patients with rare diseases in response to Senator Metzenbaum's column (The Last Word, Bio/Technology 10:464, April).

Lilly has only one product, Humatrope (somatropin, rDNA origin), a human growth hormone (hGH), that is classified as an orphan drug. At this point it is uncertain whether Humatrope will reach the $\$ 200$ million sales threshold contemplated in S.2060 before its period of exclusivity expires. We have taken no position on Senator Metzenbaum's amendment to the Orphan Drug Act; this legislation would affect our company very little, if at all.

Lilly is not actively pursuing any orphan drug designation for any other product at this time, a situation due primarily to Congress's continual threats to rewrite the rules governing this unique pharmaceutical category. On top of the already massive risks involved in drug discovery, the uncertainty these threats produce makes it utterly impossible to estimate the possibilities of success for orphan drugs.

Companies in our industry are accustomed to risking enormous sums on research with absolutely no guarantee of success. The persistent suggestion that rules might be altered after the risks have been accepted and the dollars spent has helped persuade Lilly to devote our research resources to critical therapeutic areas other than "orphan" diseases.

For your readers' reference and perspective, a few facts about Lilly's Humatrope experience may be helpful. Although an exact figure for research investment in a specific drug cannot be calculated, even a partial tabulation of Lilly's R\&D investment in hGH reveals more than $\$ 60$ million in direct costs. This figure omits many categories of spending, such as basic research costs, the cost of equipment necessary to develop and produce the product, and, most importantly, the opportunity cost of the money involved. A conservative estimate of this capital cost would push Lilly's hGH expenditures far above $\$ 100$ million. Under this analysis, we have only recently managed to recover our research investment: we have yet to recoup our manufacturing and marketing costs or the return to our shareholders.

Despite the enormous cost of its discovery and development, Humatrope was introduced to the market at 25 percent less than the price of the product it replaced. (That product, incidentally, was taken off the market after several patients died from a viral disease which contaminated the product.) Humatrope's price has never been increased in its five years of availability.

Lilly's sense of social responsibility to patients does not stop with pricing policy. From the outset, the company has funded a grant program to ensure that Humatrope would be available to all children who need it, regardless of ability to pay. Last year, nearly one of every 10 patients received Humatrope free. Only seven applications for free Humatrope have ever been denied, some of those due to evidence that an unapproved use was intended.

Lilly believes the Orphan Drug Act has clearly worked. The world has miraculous new medicines that would not otherwise have been discovered and developed. If Congress nonetheless is determined to rewrite the act, so be it; our only recommendation would be that this be the last such action. Scientists who measure their research horizons in decades and their investments per drug in hundreds of millions of dollars cannot cope with laws that may change in midstream, changing with them the basic covenant on which careers and huge sums were risked.

Mitchell E. Daniels, Jr. Vice President, Corporate Affairs Eli Lilly and Co. Lilly Corporate Center Indianapolis, IN 46285

\section{To the editor:}

I read the recent commentary concerning FDA approvals with great interest (Bio/Technology 10:488-490, R. Brandon Fradd). I was particularly impressed with the clear conceptual explanations of the statistical issues involved in the data analysis. I was curious, however, about the second description of the Type I error rate. Isn't "a 95\% chance that the benefit the drug produces is in fact a real benefit and not a random event" mixing up $1-\alpha$ and $1-\beta$ ? My thought was that $95 \%$ is $1-\alpha$ which is to correctly accept the null hypothesis, whereas the second description addresses the probability of correctly rejecting the null hypothesis. As a related aside, the first description ("there is less than a 5 percent chance that the difference between the treated and untreated groupsisarandom occurrence") is also better in not assigning causality. A statistically significant effect may be unlikely by chance alone but the experimental design is the foundation on which specific alternatives (i.e., a drug effect) must rest. In any case, your article was a great explanation of the process and I wish I could be so clear when consulting. Finally, I was intrigued by the explanation of how the FDA handles multiple comparisons (e.g., planned comparisons). In a time when most editors allow uncorrected $t$-tests to be published in the absence of an official journal policy, it's refreshing to see someone taking a conscious stand on the issue. Are the FDA policies on multiple comparisons codified and written down? I deal with experimental data and not regulatory statistics but it would be very helpful to read over the FDA procedures. Again, congratulations on an excellent educational effort.

David S. Reasner Research Associate Worcester Foundation for Experimental Biology 222 Maple Avenue Shrewsbury, MA 01545 